Cinémas

Revue d'études cinématographiques

Journal of Film Studies

\title{
Bibliographie sélective sur le scénario
}

\section{Renée Gaulin}

Volume 2, numéro 1, automne 1991

Le Scénario

URI : https://id.erudit.org/iderudit/1001056ar

DOI : https://doi.org/10.7202/1001056ar

Aller au sommaire du numéro

Éditeur(s)

Cinémas

ISSN

1181-6945 (imprimé)

1705-6500 (numérique)

Découvrir la revue

Citer ce document

Gaulin, R. (1991). Bibliographie sélective sur le scénario. Cinémas, 2(1), 149-152.

https://doi.org/10.7202/1001056ar d'utilisation que vous pouvez consulter en ligne.

https://apropos.erudit.org/fr/usagers/politique-dutilisation/ 


\section{Bibliographie sélective sur le scénario}

\section{Renée Gaulin}

\section{Livres et périodiques}

«Adaptations» (collectif), Avancées cinématographiques, nos 10 et $11,2^{\mathrm{e}}$ trimestre, 1985 .

"Cinéma français: l'enjeu scénario», Cahiers du cinéma, nos 371372 (mai 1985).

«Les Scénaristes» (collectif), Cinématographe, no 53 [s.d.].

«Scénariser» (collectif), Lumières, no 22 (printemps 1990).

BEVERIDGE, James A. Le Scénario du film de court métrage. Paris: Unesco, 1969.

BRADY, Ben. The Understructure of Writing for Film and Television. Austin: U. of Texas Press, 1988.

Caméra/Stylo, Scénario (collectif). Paris, s.e., 1983.

CARRIÈRE, Jean-Claude et BONITZER, Pascal. Exercice du scénario. Paris: Femis 1990.

CHION, Michel. Écrire un scénario. Paris: Cahiers du cinéma/INA, 1985.

CORCISS, Richard. Talking Pictures: Screenwriters in the American Cinema, 1927-1973. New York: Overlook Press, 1974.

CUCCA, Antoine. L'Écriture du scénario. Paris: Dujarrie, 1986.

DMYTRYK, Edward. On Screen Writing. Boston: Focal Press, 1985. 
FIELD, Syd. Screenplay: The Foundations of Screenwriting. New York: Delacorte Press, 1982.

FIELD, Syd. Le Scénario. Montréal: Merlin, 1990.

GARCIA, Alain. L'Adaptation $d u$ roman au film. Paris: Diffusion, 1990.

HERMAN, Lewis. A Practical Manual of Screen Playwriting for Theater and Television Films. New York: New American Library, 1974.

HORTON, Andrew S. et Magretta, Joan. Modern European Filmakers and the Art of Adaptation. New York: Frederick Ungar Publishing, 1981.

Importance du scénario (collectif). Montréal: Cinémathèque québécoise/Musée du Cinéma, 1982.

Le Paradoxe du scénariste: dossiers documentaires de l'Institut national de la communication audiovisuelle (collectif). Paris: INA, 1983.

MAILLOT, Pierre. L'Écriture cinématographique. Paris: Méridiens Klincksieck, 1989.

PEETEIS, Benoît (dir.). Autour du scénario. Cinéma, bande dessinée, roman-photo, vidéo-clip, publicité, littérature. Bruxelles: Revue de l'Université de Bruxelles, 1986.

PELLETIER, Esther. «Le Scénario et le cinéma québécois», Québec français, no 51 (octobre 1983) p. 36-39.

PELLETIER, Esther. «L'Écriture du scénario: une hypothèse de construction des personnages", Cinéma et personnages: cinq points de vue. Québec: Musée de la civilisation, 1991, p. 7-30.

PELLETIER, Esther. «L'Implantation de la fiction et de la scénarisation dans l'industrie du cinéma québécois», Le Cinéma québécois des années 80. Montréal: Cinémathèque québécoise/Musée du cinéma, 1989, p. 98-109.

RAYNAULD, Isabelle. «Le Point de vue dans le scénario», in «Le Point de vue fait signe», Protée, vol. XVI, nos 1-2 (hiverprintemps 1988) p. 156-160. 
RILLA, Wolf. The Writer and the Screen. On Writing for Film and Television. London: W. H. Allan, 1973.

SALE, Christian. Scénaristes au travail. Renens: Hatier, 1981.

SWAIN, Dwigt V. Film Scriptwriting. A Practical Manuel. Boston: Focal Press, 1982.

TOROK, Jean-Paul. Le Scénario. L'Art d'écrire un scénario. Bruxelles: éd. de l'Université de Bruxelles, 1986.

VALE, Eugénie. The Technique of Screenplay Writing. An Analysis of the Dramatic Structure of Motion Pictures. New York: Grosset and Dunlop, 1972.

VAN NYPELSEER-WOLFOWICZ, Jacqueline. «Outils d'analyse du scénario», Les Cahiers du scénario, nos 2-3 (1987).

VISWANATHAN, Jacqueline. «Une histoire racontée en images», Études françaises, vol. 22, no 2 (hiver 1987).

\section{Thèses non publiées}

DUFRESNE, Maryse. L'Évolution du scénario dans l'histoire du cinéma. Mémoire de maîtrise. Université de Montréal: Département de l'histoire de l'art, 1990.

PALESIS, Ioannis Antonios. At the Crossroads of Cinéma and Littérature: A Study of the Scénario as a Genre. Thèse (Ph.D.). U. of Pennsylvania, 1979.

PELLETIER, Esther. Le Cinéma de fiction: discours d'action et discours de narration. Mémoire de maîtrise. Université Laval: Département des littératures, 1981.

PELLETIER, Esther. Écrire un scénario. Le scénario et l'industrie du cinéma québécois. Thèse (Ph.D.). Université Laval: Département des littératures, 1990.

RAYNAULD, Isabelle. Le Scénario de film comme texte. Histoire, théorie et lecture(s) du scénario, de Georges Méliès à Marguerite Duras et Jean-Luc Godard. Thèse (Ph.D.). Université de Paris VII, 1990.

ROSEN, Marc Rodney. Writing for the screen. Thèse (Ph.D). Northwestern University, 1982. Ann Arbœ: University Microfilms International, 1986. 
TOLES, George E. Film/Literature. Thèse (Ph.D.). Winnipeg: University of Manitoba, 1983.

UMLAND, Samuel Joseph. Sunless Sea: Genesis of a Motion Picture Screenplay. Thèse (Ph.D.). University of Nebraska, 1987. Ann Arbœ: University Microfilms International, 1988.

Université Laval 